\title{
ERRATUM
}

\section{Antimicrobial Effect of Korean Propolis Against the Mutans Streptococci Isolated from Korean}

Min Jung Kim ${ }^{1 \dagger}$, Chun Sung Kim ${ }^{1 \dagger}$, Byung-Hoon Kim ${ }^{2 \dagger}$, Sang-Bok Ro ${ }^{2}$, Yun Kyong Lim ${ }^{1}$, Soon-Nang Park ${ }^{1}$, Engene Cho ${ }^{1}$, Jang-Hyuk $\mathrm{Ko}^{2}$, Soon-Sung Kwon ${ }^{2}$, Yeong-Mu Ko ${ }^{2}$, and Joong-Ki Kook ${ }^{1 *}$

${ }^{1}$ Department of Oral Biochemistry, ${ }^{2}$ Department of Dental Materials, School of Dentistry, Chosun University, Gwangju 501-759, Republic of Korea (Received January 3, 2011 / Accepted January 26, 2011)

In the article by Kim et al. that appears in the Journal of Microbiology 2011; 49, 161-164. Page 1617 th author name Engene Cho should be changed as Eugene Cho. 